\title{
Efficiency Analysis of Provincial Tourist Attractions in China Based on DEA-Malmquist Model
}

\author{
Zhen $\mathrm{Su}$ \\ Business School \\ Guangxi University \\ Nanning, China 530004
}

\author{
Huike Shi \\ Business School \\ Guangxi University \\ Nanning, China 530004
}

\author{
Chuanyang Ren \\ Business School \\ Guangxi University \\ Nanning, China 530004
}

\begin{abstract}
This paper analyzes the static efficiency and dynamic efficiency of provincial tourist attractions in China from 2004 to 2015 by using DEA-Malmquist model. Research founding: It is found that the overall technical efficiency of tourist attractions in China is not high, so there is still a large room for improvement, and the pure technical efficiency is the short board. Judging from the three regions, comprehensive technical efficiency in the eastern region is the highest while that of the central region is the lowest. From the three time sections of 2004, 2009 and 2015 , it can be seen that the number of provinces with increasing returns to scale is increasing. Malmquist index analysis shows that the total factor productivity of tourist attractions in China as a whole continues to progress, but the provinces can be divided into three types of rapid growth, growth and regression.
\end{abstract} index

Keywords-tourist attractions; efficiency; DEA; Malmquist

\section{INTRODUCTION}

Scenic areas are the important places for tourism activities, as well as the indispensable force in the tourism economy. "Chinese Tourism Investment Report" issued by National Tourism Administration in 2016 points out that in recent years, investment in scenic area in China maintains steady growth. At the same time, the "13th five-year" tourism development plan of China proposes to further strengthen the re-check and exit mechanism for A-level scenic areas. This shows that both the traditional scenic spots and emerging areas will face the pressure to improve the quality of management services and operating efficiency. Therefore, the evaluation of the efficiency of scenic areas and the diagnosis of short board has become objective needs. In fact, in recent years, study on the development of scenic spots in China and the relative gap from the perspective of efficiency has become a new branch of research on scenic spots. On the one hand, the eco-efficiency evaluation of the

Fund Project: Guangxi University Research Fund Project (XBS12005); China Postdoctoral Science Fund Project (2016M590847), Guangxi Postdoctoral Special Project scenic spots in the micro-level is of great concern. The related research is mainly based on ecological footprint method, network DEA method and meterage regression equation.[1], [2], [3] On the other hand, the research objects are restricted in various national tourist attractions, and the comprehensive efficiency of scenic spots is mainly analyzed by using DEA and other methods.[4], [5], [6] Exploring the development efficiency of tourist attractions from the macro perspective of China is conducive to the larger scale analysis of the efficiency development trend of this industry. Although Li Zhiyong (2013) and Xu Bo (2016) [7], [8]have explored the efficiency of service in scenic area within a certain area, there is still a lack of macro efficiency analysis with the combination of static and dynamic state in macroscopic provincial scale. There is room for further discussion on the efficiency measurement in this field. Therefore, this paper plans to use DEA-Malmquist model to analyze the efficiency of provincial tourism scenic area of China in the past 10 years.

\section{RESEARCH METHODS AND DATA SOURCES}

\section{A. Data Envelopment Analysis}

Data Envelopment Analysis (DEA) is an evaluation method used to deal with multi-input and multi-output efficiency. This method was first created by A. Charnes in 1978, which uses the data to plan the model, and make analysis on the input and output efficiency of decisionmaking unit (DMU) according to the sample data. The radial models commonly used by DEA include CCR and BCC models, which are based on the different hypothesis of constant returns to scale and variable returns to scale. Specifically, if we assume that there are n DMUs and the decision units have $\mathrm{m}$ input variables and $\mathrm{q}$ output variables, they are expressed as $x 1 \mathrm{j}, \mathrm{x} 2 \mathrm{j}, \ldots, \mathrm{xmj}$ and $\mathrm{y} 1 \mathrm{j}, \mathrm{y} 2 \mathrm{j}, \ldots$, yqj respectively. $\lambda j$ is the weight vector of input and output of each scenic spot in China. The efficiency evaluation index $\varphi$ of the decision-making unit DMUj based on the outputoriented BCC model should satisfy: 


$$
\begin{aligned}
& \max \phi \\
& \text { s.t. } \sum_{j=1}^{n} \lambda_{j} x_{i j} \leq x_{i 0} \\
& \sum_{j=1}^{n} \lambda_{j} y_{r j} \geq \phi y_{r 0} \\
& \sum_{j=1}^{n} \lambda_{j}=1 \\
& \lambda \geq 0, \mathrm{j}=1,2, \cdots, \mathrm{n}
\end{aligned}
$$

The comprehensive efficiency of the tourism industry in each provincial tourist attractions in China can be calculated by (1) and its dual model. The comprehensive efficiency calculated by BCC model can be decomposed into pure technical efficiency and scale efficiency, namely, comprehensive technical efficiency (CRSTE) $=$ pure technical efficiency (VRSTE) $\times$ scale efficiency (SCALE). Among them, the pure technical efficiency refers to the efficiency of tourist area affected by management and technology and other factors while scale efficiency is affected by the scale factors of tourist attractions. The smaller one of two values is the constraint of the comprehensive technical efficiency.

\section{B. Malmquist Index Model}

In order to analyze the efficiency of provincial tourist attractions in China from the dynamic point of view, the Malmquist index based on panel data is used to measure the efficiency. The Malmquist index was first proposed by the Swedish scholar Malmquist in 1953. Then, Fare et al. combined it with data envelopment analysis to establish the Malmquist index which can analyze the total factor productivity change of (TFPch) in different periods, and make it a widely used efficiency analysis method. The formula is:

$$
\begin{aligned}
& \text { TFPch }=M_{i}\left(x_{t+1}, y_{t+1} ; x_{t}, y_{t}\right) \\
& =\sqrt{\frac{D_{i}^{t}\left(x_{t+1}, y_{t+1}\right)}{D_{i}^{t}\left(x_{t}, y_{t}\right)} \times \frac{D_{i}^{t+1}\left(x_{t+1}, y_{t+1}\right)}{D_{i}^{t+1}\left(x_{t}, y_{t}\right)}} \\
& =\frac{D_{i}^{t+1}\left(x_{t+1}, y_{t+1}\right)}{D_{i}^{t}\left(x_{t}, y_{t}\right)} \\
& \times \sqrt{\frac{D_{i}^{t}\left(x_{t+1}, y_{t+1}\right)}{D_{i}^{t+1}\left(x_{t+1}, y_{t+1}\right)} \times \frac{D_{i}^{t}\left(x_{t}, y_{t}\right)}{D_{i}^{t+1}\left(x_{t}, y_{t}\right)}} \\
& =\operatorname{Effch}\left(x_{t+1}, y_{t+1} ; x_{t}, y_{t}\right) \times T E c h\left(x_{t+1}, y_{t+1} ; x_{t}, y_{t}\right)
\end{aligned}
$$

Malmquist index formula (2) can measure the total factor productivity change during $t$ period to $t+1$ period. Total factor productivity can be further decomposed into technical change index (TEch) and efficiency change index (Effch). In the case of constant returns to scale, the efficiency change (Effch) can be decomposed again into pure technical efficiency change (PEch) and scale efficiency change (SEch), namely:

$$
T F P_{c h}=P E_{c h} \times S E_{c h} \times T E_{c h}
$$

When TFPch $>1$, it indicates that total factor productivity rises; when TFPch $<1$, it indicates that total factor productivity reduces and TFPch $=1$ indicates the productivity remains constant. Effch represents the ratio of the technical efficiency value of the evaluated DMU in $t+1$ period to the technical efficiency value in $t$ period. When Effch $>1$, it indicates the technical efficiency improves, and when Effch $<1$, it means the technical efficiency reduces. TEch represents the change in technology, reflecting the impact of changes in the two leading edges on total factor productivity. When TEch> 1, it indicates technological progress, and TEch $<1$ means retrogress of technology. PEch represents the change in pure technical efficiency. When PEch> 1, it indicates that the technical application level increases, when PEch $<1$, it means the level reduces. SEch represents the change in scale efficiency, so when SEch $>1$, it means the scale efficiency raises, while when SEch $<1$, it reflects the scale efficiency reduces.

\section{Index Selection and Data Sources}

This paper chooses 29 provinces, autonomous regions and municipalities with relatively complete statistics of tourist attractions as the decision-making units DMU (excluding Tibet, Anhui, Taiwan, Hong Kong and Macao), and take the panel data after the SARS incident as research sample. In regard to the input indicators, input of capital and manpower are common input indicators, so the original price of fixed assets (million) and employees (people) are chosen as the input indicators of tourist attractions. In terms of output indicators, taking into account the reality of operating income of scenic areas and profits, the author selects the operating income (million) and profits (million) respectively as the output indicators. The relevant data are from 20052016 "Tourism Statistical Yearbook of China", with strong authority and reliability. In the case of missing data processing, the missing data of 2010 are omitted, and a small number of missing data are replaced by the data in adjacent years of this DMU. Research uses MaxDEA software for data processing.

\section{ANALYSIS ON THE EFFICIENCY OF TOURIST ATTRACTIONS}

\section{A. Efficiency Situation of Tourist Attractions}

The comprehensive technical efficiency of tourist attractions is not high, so there is a large distance from the optimal efficiency gap. From 2004 to 2015, the mean value of comprehensive technical efficiency of tourist attractions in China is 0.485 , which differs from the optimal level by $51.5 \%$, indicating that there is still room for improvement in the efficiency of tourist attractions development and operation in China. The author decomposed the comprehensive technical efficiency and finds that the national average of pure technical efficiency is 0.631 and the national average of scale efficiency is 0.769 . The relatively low pure technical efficiency is the main factor restricting the improvement of comprehensive efficiency. It can be seen 
that the problems in operation of tourist attractions such as idle property, inefficient use of resources and insufficient investment in science and technology are relatively prominent. At the same time, the tourist area as a whole has not been able to achieve the best scale efficiency, since there is still room for improvement of $23.1 \%$ compared with the effective surface.

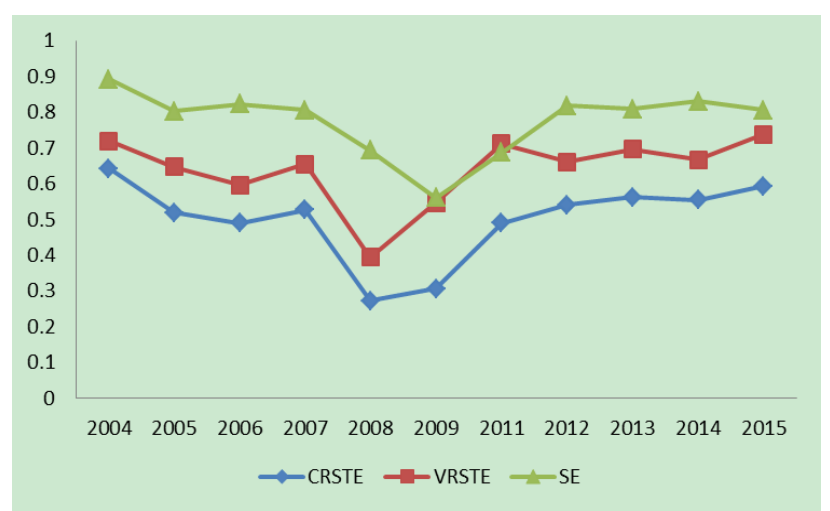

Fig. 1. Efficiency of scenic area in China in 2004-2015 and its decomposition trend.

From the time changing trends in "Fig. 1", it can be seen that the comprehensive technical efficiency of tourist attractions in China has experienced the U-shaped development trend that decreases at first and then rises. The highest value of comprehensive technical efficiency was 0.642 in 2004, then decreased year by year and reached the lowest value of 0.273 in 2008 , which decreased by 0.363 . After 2008, the comprehensive efficiency value of the tourist attractions in China increased year by year, and reached 0.593 in 2015. When the comprehensive efficiency is decomposed into pure technical efficiency and scale efficiency, the pure technical efficiency also experience the U-type development trend like scale efficiency, and the scale efficiency curve is overall higher than the pure technical efficiency (except 2011). It can be seen that the scale efficiency is the main reason that drive the improvement of the comprehensive technical efficiency of tourist attractions in China. The shortage of resources and technology application is the main shortcoming of the improvement of comprehensive technical efficiency.

\section{B. Analysis of Differences of Three Regions in the Efficiency of Tourist Attractions}

Over the past 10 years, the comprehensive efficiency of the tourist attractions in eastern, central and western China has shown the state of the east $(0.504)>$ west $(0.477)>$ central area (0.468), and there is some fluctuation. The fluctuation trend can be divided into three stages: the first stage (2004-2006) — the overall comprehensive efficiency of tourist attractions in the three areas reduces, and the difference between regions is not big. The second stage (2006-2011) - comprehensive efficiency of tourist attractions in various regions show differentiation and volatility of different degrees. Among them, changes of the eastern and western parts have obvious time synchronization, and jointly experience the peak in 2007 and the low ebb in
2008, which also reflects that eastern and western provinces and regions are significantly influenced by the global financial crisis. After 2008, the two regions began to recover gradually and returned to the efficiency level of 2006 in 2011. In contrast, central region in China is relatively stable, indicating that the comprehensive efficiency of its scenic area is not significantly affected by external factors. The third stage (2011-2015) — the three areas enter a stable period of development and new differentiation emerges. The comprehensive efficiency of eastern region is significantly higher than that of the central and western regions.

Further decomposition shows that in recent years the main factor that drives the level of comprehensive efficiency is the scale efficiency. After the eastern region experiencing the volatility in 2008-2009, the pure technical efficiency continued to maintain higher than that of the central and western regions, and continued to maintain the high level of $0.83-0.85$. This indicates that in recent years the eastern region gradually takes lead in the resource efficiency allocation of tourist attractions, management services, and technical content in China. Since 2009, the gap between pure technical efficiency of the central and western region is not large, but that of the western region is slightly higher than that of the central region. We can see the contribution of management and services to the efficiency in western area are greater than that of the central region. In regard to the scale efficiency, the overall gap between the scale efficiency of three regions in fluctuation is not large, but the scale efficiency of central region is more prominent. Over the past 10 years, the scale efficiency of the tourist attractions in central region holds the lead in about $90 \%$ of the years as shown in "Fig. 2".
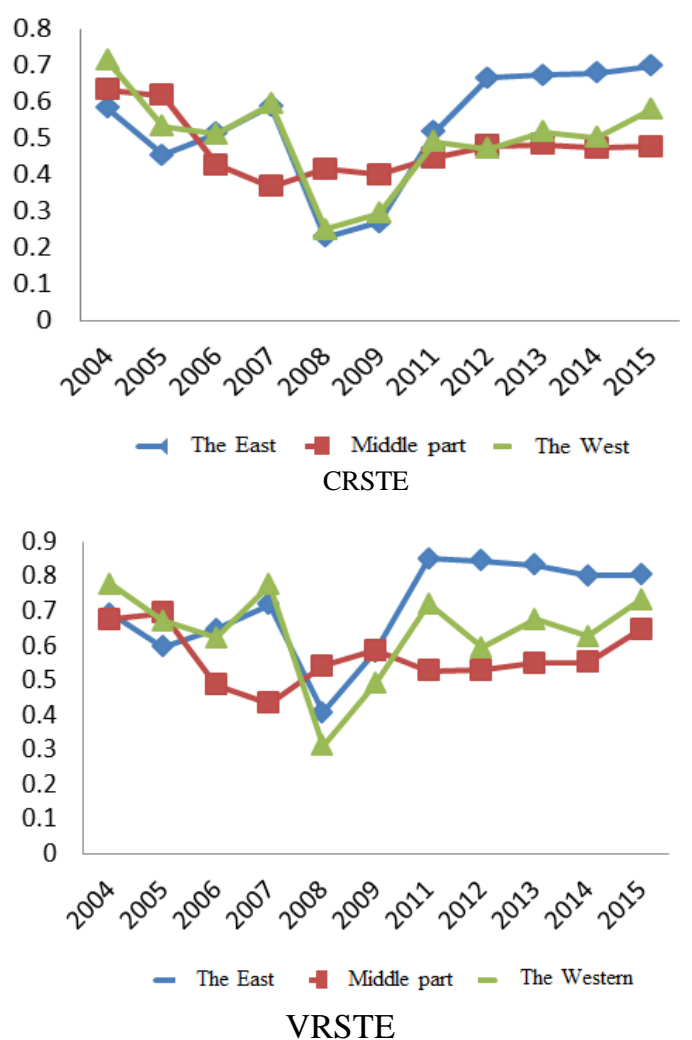


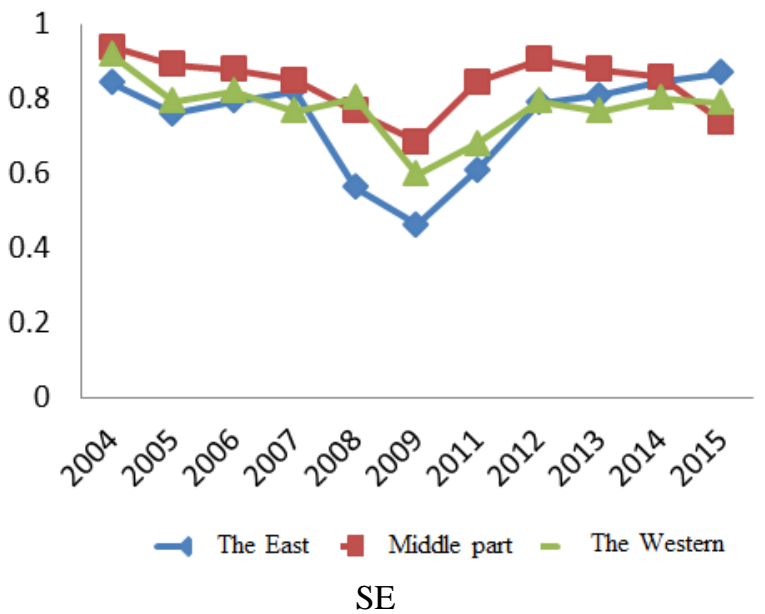

Fig. 2. The efficiency and decomposition trend of scenic areas in eastern and central regions of China.

\section{Provincial Cross-section Analysis of Efficiency of Tourist Attractions}

Among them, 2004, 2009 and 2015 are extracted to be compared, and it is found that the efficiency characteristics of the tourist attractions in different provinces of China are different. The number of provinces (districts / municipalities) with comprehensive efficiency over the mean of 2004, 2009 and 2015 is 16,14 and 18 respectively. The number of provinces (districts / cities) that are effective in comprehensive efficiency in the three time sections is 6,2 and 3 respectively. The provinces that are effective at least once in the three years are Shanghai, Jiangxi, Henan, Hainan, Guizhou, Shaanxi, Ningxia and Xinjiang. There are provinces that once rank the forefront in efficiency in eastern, central and western regions.

TABLE I. EFFiciency List OF TOURIST ATtRACTIONS In EACH PROVINCE IN 2004, 2009 AND 2015

\begin{tabular}{|c|c|c|c|c|c|c|c|c|c|c|c|c|}
\hline & \multicolumn{4}{|c|}{2004} & \multicolumn{4}{|c|}{2009} & \multicolumn{4}{|c|}{2015} \\
\hline DMU & crste & vrste & scale & $\mathbf{R S}$ & crste & vrste & scale & $\mathbf{R S}$ & crste & vrste & scale & RS \\
\hline mean value & 0.642 & 0.719 & 0.892 & - & 0.306 & 0.546 & 0.560 & - & 0.593 & 0.737 & 0.805 & - \\
\hline Beijing & 0.614 & 0.842 & 0.728 & DRS & 0.261 & 0.463 & 0.563 & DRS & 0.628 & 0.646 & 0.971 & IRS \\
\hline Tianjin & 0.252 & 0.259 & 0.973 & IRS & 0.137 & 0.164 & 0.836 & IRS & 0.839 & 1.000 & 0.839 & IRS \\
\hline Hebei & 0.534 & 0.559 & 0.955 & DRS & 0.153 & 0.489 & 0.312 & DRS & 0.335 & 0.336 & 0.998 & IRS \\
\hline Shanxi & 0.851 & 0.928 & 0.917 & DRS & 0.211 & 0.262 & 0.804 & DRS & 0.281 & 0.299 & 0.940 & IRS \\
\hline Inner Mongolia & 0.657 & 0.666 & 0.988 & DRS & 0.250 & 0.287 & 0.871 & DRS & 0.417 & 0.423 & 0.985 & DRS \\
\hline Liaoning & 0.437 & 0.552 & 0.793 & DRS & 0.200 & 0.491 & 0.408 & DRS & 0.542 & 0.666 & 0.813 & IRS \\
\hline Jilin & 0.160 & 0.164 & 0.975 & IRS & 0.469 & 0.475 & 0.987 & DRS & 0.308 & 0.349 & 0.882 & IRS \\
\hline Heilongjiang & 0.544 & 0.548 & 0.992 & IRS & 0.607 & 0.682 & 0.889 & IRS & 0.257 & 1.000 & 0.257 & IRS \\
\hline Shanghai & 1.000 & 1.000 & 1.000 & CRS & 0.942 & 1.000 & 0.942 & DRS & 1.000 & 1.000 & 1.000 & CRS \\
\hline Jiangsu & 0.359 & 0.628 & 0.573 & DRS & 0.262 & 0.589 & 0.444 & DRS & 0.691 & 0.996 & 0.694 & DRS \\
\hline Zhejiang & 0.552 & 0.754 & 0.731 & DRS & 0.224 & 0.439 & 0.509 & DRS & 0.653 & 0.839 & 0.778 & DRS \\
\hline Fujian & 0.853 & 0.855 & 0.998 & DRS & 0.359 & 0.946 & 0.380 & IRS & 0.673 & 0.750 & 0.898 & DRS \\
\hline Jiangxi & 1.000 & 1.000 & 1.000 & CRS & 0.372 & 0.830 & 0.449 & DRS & 1.000 & 1.000 & 1.000 & CRS \\
\hline Shandong & 0.433 & 0.638 & 0.678 & DRS & 0.297 & 0.823 & 0.361 & DRS & 0.859 & 1.000 & 0.859 & DRS \\
\hline Henan & 1.000 & 1.000 & 1.000 & CRS & 0.575 & 0.780 & 0.737 & DRS & 0.632 & 0.765 & 0.826 & DRS \\
\hline Hubei & 0.714 & 1.000 & 0.714 & DRS & 0.789 & 1.000 & 0.789 & DRS & 0.524 & 0.614 & 0.853 & DRS \\
\hline Hunan & 0.772 & 0.773 & 0.999 & DRS & 0.164 & 0.433 & 0.378 & DRS & 0.768 & 0.976 & 0.787 & DRS \\
\hline Guangdong & 0.991 & 1.000 & 0.991 & DRS & 0.132 & 1.000 & 0.132 & DRS & 0.772 & 1.000 & 0.772 & DRS \\
\hline Guangxi & 0.719 & 0.746 & 0.964 & DRS & 0.333 & 0.475 & 0.700 & DRS & 0.901 & 0.909 & 0.992 & IRS \\
\hline Hainan & 1.000 & 1.000 & 1.000 & CRS & 0.615 & 0.698 & 0.882 & DRS & 1.000 & 1.000 & 1.000 & CRS \\
\hline Chongqing & 0.498 & 0.500 & 0.996 & DRS & 0.137 & 0.176 & 0.782 & DRS & 0.564 & 0.598 & 0.944 & DRS \\
\hline Sichuan & 0.675 & 1.000 & 0.675 & DRS & 0.690 & 1.000 & 0.690 & DRS & 0.668 & 0.691 & 0.968 & DRS \\
\hline Guizhou & 0.496 & 0.497 & 0.998 & DRS & 1.000 & 1.000 & 1.000 & CRS & 0.680 & 0.966 & 0.703 & IRS \\
\hline Yunnan & 0.999 & 1.000 & 0.999 & IRS & 0.108 & 0.135 & 0.800 & DRS & 0.490 & 0.529 & 0.926 & DRS \\
\hline Shanxi & 1.000 & 1.000 & 1.000 & CRS & 0.689 & 0.694 & 0.992 & IRS & 0.740 & 0.853 & 0.867 & DRS \\
\hline Gansu & 0.537 & 0.537 & 1.000 & IRS & 0.140 & 0.177 & 0.791 & DRS & 0.651 & 0.911 & 0.714 & IRS \\
\hline Qinghai & 0.608 & 1.000 & 0.608 & IRS & 0.033 & 1.000 & 0.033 & IRS & 0.371 & 1.000 & 0.371 & IRS \\
\hline Ningxia & 1.000 & 1.000 & 1.000 & CRS & 0.520 & 1.000 & 0.520 & IRS & 0.624 & 0.745 & 0.838 & IRS \\
\hline Xinjiang & 0.939 & 0.941 & 0.998 & DRS & 1.000 & 1.000 & 1.000 & CRS & 0.460 & 0.700 & 0.657 & IRS \\
\hline
\end{tabular}

The comprehensive efficiency is further decomposed into purely technical efficiency and scale efficiency, which can clearly affect the major shortcomings of the comprehensive technical efficiency of the provinces (autonomous regions/ municipalities). In the three sections, the provinces that achieve efficiency in pure technical efficiency at least once but have inefficient scale effective are: Tianjin, Heilongjiang, Shandong, Hubei, Guangdong, Sichuan, Yunnan, and Qinghai. The data show that the scenic area of the abovementioned provincial area has better management ability and resource allocation efficiency, and can improve the comprehensive technical efficiency of regional scenic area by improving the scale efficiency. At the same time, the province with scale efficiency achieving effective at least once but pure technical maintaining inefficient is Gansu. The data show that the province should further enhance the management efficiency and resource allocation level of the scenic area on the basis of maintaining the scale efficiency. The degree of change in pure technical efficiency and scale efficiency also shows different combinations over time. 
Compared with 2004, the numbers of provinces (regions / municipalities) with reduced and improved technical efficiency in 2009 was 14 and 7 respectively, and the numbers of provinces (regions / cities) with reduced and improved scale efficiency was 23 and 5. The mean values of change in pure technical efficiency and scale efficiency are 0.173 and 0.332 respectively. Compared with 2009, the numbers of provinces (regions / cities) with decreased and improved pure technical efficiency are 9 and 17 respectively, and the numbers of provinces (districts / cities) with reduced and improved scale efficiency are 6 and 23 respectively. The mean values of change in pure technical efficiency and scale efficiency are 0.191 and 0.245 respectively. Overall, the mean value of efficiency of tourist attractions and its decomposition shows that the scale efficiency has played a greater role. This conforms to the reality that in recent years, tourist attractions speed up the development and pursue the scale expansion under the leadership of the government.

From the returns to scale, it can be seen that there are many provincial tourist attractions in China in the state of declining returns to scale. In 2004, 2009 and 2015, the numbers of provinces (districts/ cities) with declining returns to scale were 17, 21 and 13 respectively. Among them, returns to scale of Inner Mongolia, Jiangsu, Zhejiang, Shandong, Hubei, Hunan, Guangdong, Chongqing and Sichuan decreased in three years. In the same period, the numbers of provinces (districts/ cities) with increasing returns to scale are 6, 6 and 13 respectively. Among them, the returns to scale of Tianjin, Heilongjiang and Qinghai are always increasing. In the same period, the numbers of provinces (district/ city) with constant returns to scale are 6, 2 and 3 respectively and there is no province with returns to scale remaining unchanged all the time. The analysis of returns to scale shows that the number of provinces with increasing returns to scale gradually increases and the development of provincial tourist attractions in China gradually enters the stage where improvement of quality and efficiency becomes the focus.

\section{DYNAMIC ANALYSIS OF EFFICIENCY OF TOURIST ATTRACTIONS}

\section{A. Overview of Total Factor Productivity Index of Tourist Attractions in China}

Analyzed from the dynamic sequential change, resource utilization efficiency of tourist attractions in China remain in the overall increasing state. It is calculated that the Malmquist Total Factor Productivity Index $\left(\mathrm{TFP}_{\mathrm{ch}}\right)$ is greater than 1 in more than ten years, indicating that the total factor productivity of tourist attractions is progressing and the average annual growth rate reaches $5.8 \%$. This also means that the use of various input factors in the development process of tourist attractions in China continues to be enhanced, so the utilization efficiency has been improved. Among them, the technical change contributes 6.7 percentage points, but the technical efficiency changes decreases by 0.8 percentage points, which indicates that the promoting function of technical progress of tourist attractions in China is significant. From the perspective of change in total factor productivity, in the past ten years, only 2006-2007, 2008-2009 and 2014-2015 shows the decline of $6.8 \%, 9.3 \%$ and $0.7 \%$ respectively, and the rest years shows increase. The two periods with the largest increases are 2007-2008 and 2009-2011, an increase of 39.6\% and 30.9\%. Judging from the data, there may be correlation between the fluctuation of Malmquist index of tourist attractions in China and the idle resource utilization of tourist attractions during the global financial turmoil in 2008 and the rapid rebound of tourism after financial crisis.

After the further decomposition of total factor productivity index $\left(\mathrm{TFP}_{\mathrm{ch}}\right)$ of Malmquist, it can be found that there is fluctuation between the technical change index $\left(\mathrm{TE}_{\mathrm{ch}}\right)$ and technical efficiency change index $\left(\mathrm{Eff}_{\mathrm{ch}}\right)$. Among them, the average annual increase of technology index change is $6.7 \%$, the average annual decline of technical efficiency index is $0.8 \%$ per year, indicating that the growth of total factor productivity index $\left(\mathrm{TFP}_{\mathrm{ch}}\right)$ is mainly caused by technological progress, while the progress of technical efficiency is slow, and even affect the improvement of total factor productivity. Accordingly, the development of tourist attractions in China can be divided into three stages: the first stage (2004-2006) is the period when the technological change is greater than 1 and technical efficiency changes is less than 1, indicating that development of tourist attractions in China enter the period of accelerating technical progress and construction in "post-SARS" period; the second stage (2006-2009) is the period when technological change and technological efficiency change fluctuate violently due to the external economic environment and other factors; the third stage (2009-2015) is the period when total factor productivity index $\left(\mathrm{TFP}_{\mathrm{ch}}\right)$ remains above 1 (slightly less than 1 in 2015), indicating that scenic areas in China continue to focus on improving efficiency in the context of changes in the economic environment. At the same time, the average annual increase of technological efficiency change $\left(\mathrm{PE}_{\mathrm{ch}}\right)$ is $0.2 \%$, while the average annual decline of scale efficiency change (SEch) is $1 \%$, indicating that the scientific management level of tourist attractions in China has improved steadily, but there is still room for improvement in scale efficiency.

TABLE II. MALMQUIST INDEX OF TOURIST ATTRACTIONS IN CHINA IN 2004-2015 AND DECOMPOSITION

\begin{tabular}{|c|c|c|c|c|c|}
\hline & TEch & Effch & PEch & SEch & TFPch \\
\hline 2004-2005 & 1.310 & 0.809 & 0.899 & 0.899 & 1.060 \\
\hline $\mathbf{2 0 0 5 - 2 0 0 6}$ & 1.106 & 0.944 & 0.921 & 1.025 & 1.044 \\
\hline $\mathbf{2 0 0 6 - 2 0 0 7}$ & 0.867 & 1.076 & 1.099 & 0.979 & 0.932 \\
\hline $\mathbf{2 0 0 7 - 2 0 0 8}$ & 2.696 & 0.518 & 0.602 & 0.861 & 1.396 \\
\hline $\mathbf{2 0 0 8 - 2 0 0 9}$ & 0.810 & 1.120 & 1.387 & 0.807 & 0.907 \\
\hline $\mathbf{2 0 0 9 - 2 0 1 1}$ & 0.819 & 1.599 & 1.304 & 1.227 & 1.309 \\
\hline $\mathbf{2 0 1 1 - 2 0 1 2}$ & 0.910 & 1.103 & 0.927 & 1.190 & 1.004 \\
\hline $\mathbf{2 0 1 2 - 2 0 1 3}$ & 0.981 & 1.042 & 1.053 & 0.989 & 1.022 \\
\hline $\mathbf{2 0 1 3 - 2 0 1 4}$ & 1.025 & 0.986 & 0.960 & 1.028 & 1.011 \\
\hline $\mathbf{2 0 1 4 - 2 0 1 5}$ & 0.929 & 1.070 & 1.104 & 0.969 & 0.993 \\
\hline Mean value & 1.067 & 0.992 & 1.002 & 0.990 & 1.058 \\
\hline
\end{tabular}

B. Analysis of Total Factor Productivity Index of Provincial Tourist Attractions

Analyzed from the provincial level, the total factor productivity $\mathrm{TFP}_{\mathrm{ch}}$ of tourist attractions in China are different, 
and it can be divided into three types: rapid growth, growth and regression. According to the score, the first level includes six provinces of Tianjin, Jilin, Jiangsu, Hunan, Shandong, and Liaoning, of which the total factor growth rate increase most rapidly, with the average increase of $10 \%$ $-20 \%$. From the perspective of index decomposition, technological progress, efficiency change and pure technical efficiency change contribute $8.3 \%, 5.8 \%$ and $5.9 \%$ respectively, and the scale efficiency change contributes $0.1 \%$, which shows that the technological progress is the main contributor. The above provinces are mostly eastern provinces, indicating that the application of new technologies and innovation in scenic area management in eastern region achieve significant progress. The second level includes Gansu, Shanghai, Guizhou, Hainan, Sichuan, Guangxi, Heilongjiang, Hubei, Hebei, Shaanxi, Beijing, Chongqing, Guangdong, Fujian, Zhejiang, Ningxia, Henan and Xinjiang, of which the growth rate of total factor productivity is within $10 \%$. From the perspective of index decomposition, technical progress is the main contributor (7.2\%), efficiency change, pure technical efficiency change and scale efficiency change contribute $-1.6 \%,-0.3 \%$ and $-1.3 \%$ respectively, indicating that there are still some deficiencies in the reform and innovation of management methods and the rationalization of scale of scenic areas in above provinces. The third level includes five provinces of Yunnan, Jiangxi, Qinghai, Inner Mongolia and Shaanxi since the growth rate of total factor productivity slightly regresses, with the average increase of $2.8 \%$. In the decomposition of the indexes, technical progress contributes $2.8 \%$, while the efficiency change, pure technical efficiency change and scale efficiency change contribute $-5.4 \%,-4.3 \%$ and $-1.1 \%$ respectively, indicating that although the application of new technology in above provinces obtains a certain achievement, other factors weaken the growth rate of its total factor productivity to a greater extent. We should promote the development efficiency of tourist attractions by vigorously introducing new technologies, continuously improving our innovation ability, and speeding up system innovation and management innovation.

\section{CONCLUSION}

The DEA-Malmquist model is used to analyze the efficiency of input and output of tourist attractions in China in the past 10 years. The main conclusions are as follows: (1) the comprehensive technical efficiency of tourist attractions in China has a lot of room for improvement. After Indicator decomposition it is found that the scale efficiency of scenic area is relatively high while the pure technical efficiency is the short board. The problems of idle property and low efficiency utilization in operation of tourism are more prominent. (2) Comprehensive technical efficiency of tourist attractions in the three major regions of China is east $(0.504)>$ west $(0.477)>$ central $(0.468)$. Especially after 2011 , the comprehensive technical efficiency of eastern region is significantly higher than that of other regions. During the global financial crisis around 2008, the eastern and western regions maintained more consistent wave synchronization, while the central region continued to be relatively stable. (3) Judging from the three sections of 2004, 2009, and 2015, there are provinces at the forefront of efficiency in the eastern, central and western regions. The analysis of returns to scale in the three years shows that the number of provinces with increasing returns to scale increases gradually, and the development of provincial tourist attractions in China have gradually entered the stage of improving quality and efficiency. (4) Malmquist index analysis shows that the total factor productivity of tourist attractions in China is continuously improved, with the average annual growth rate of $5.8 \%$, and technological progress is the main force to stimulate its growth. From the provincial level, the total factor productivity of the tourist attractions in China can be divided into four types: rapid growth, growth and regression.

In summary, under the influence of the macroeconomic, the overall efficiency of the scenic areas in China is not high, but is making progress continuously in fluctuations. Government departments should not only focus on the scale expansion of scenic areas and the pursuit of scale efficiency, but also promote the upgrading of scenic management level, and get benefit from the scenic management through the integration of scenic resources and innovation in management system. At the same time, it is necessary to encourage the tourist area to actively introduce high-tech means to enhance the digitization and intellectualization of scenic areas, so that the management of scenic spots can keep pace with the times in the era of mobile Internet, laying a good foundation for tourist attractions in China to improve quality.

\section{REFERENCES}

[1] Li Xin, Yang Xinjun, Sun Piling. A Comparative Study on Ecological Efficiency of Different Types of Scenic Spots - A Case Study of Huashan Scenic Spot and Datang Furong Garden. Ecological Economy, 2013(02): 290-295.

[2] Zha Jianping, Wang Tingzhi. Tourism Efficiency and Tourism Productivity Evaluation of Scenic Spots under Environmental Constraints. China Population Resources and Environment, 2015(05): 92-99.

[3] Wang Shuxin, He Hong, Wang Zhongfeng. Tourism eco-efficiency of the typical scenic spots in Qinba and the influencing factors measure. journal of southwest university (Natural science edition), 2016(10): 97-103.

[4] Zhang Yonghua. A Study on the Statistical Characteristics, Evolution Trend and Influencing Factors of the Use Efficiency of National Scenic Spots. Northwest Normal University, 2015.

[5] Yu Hu, Lu Lin, Li Yajuan. Tourism Efficiency Characteristics, Type Division and Promotion Path of Lake-type National Scenic Spots. Scientia Geographica Sinica, 2015(10): 1247-1255.

[6] Du Peng, Han Zenglin, Wang Li, et al. Study on Tourism Efficiency and Accessibility of National Scenic Spots in Liaoning Province Journal of Liaoning Normal University(Natural Science Edition), 2015(02): 248-255.

[7] Li Zhiyong. Evaluation Method of Efficiency of Tourism Scenic Spot Service - from the Perspective of Low Carbon Economy. Soft Science, 2013(06): 140-144.

[8] $\mathrm{Xu} \mathrm{Bo,} \mathrm{Liu} \mathrm{Lihua.} \mathrm{Analysis} \mathrm{of} \mathrm{efficiency} \mathrm{of} \mathrm{provincial} \mathrm{tourist}$ attractions in China based on DEA. Territory \& Natural Resources Study, 2012(05): 59-60. 